\title{
Atypical Pathogen Distribution in Chinese Hospitalized AECOPD Patients: A Multicenter Cross-Sectional Study
}

\author{
Chenye Feng,' Mingtao Xu,' \\ Jian Kang,' Fuqiang Wen, (iD) ${ }^{2}$ \\ Yahong Chen, ${ }^{3}$ Jing Zhang, (D) ${ }^{4}$ \\ Wei Xiao, ${ }^{5}$ Zhonghe Zhang, ${ }^{6}$ \\ Lan Yang, Jianmin Huo, ${ }^{8}$ Jie Cao, \\ Li Zhao, (D) ${ }^{10}$ Shuyue Xia, (D) ${ }^{11}$ \\ Yan Yin,' Wei Wang'
}

'Department of Pulmonary and Critical Care Medicine, Institute of Respiratory Diseases, First Affiliated Hospital of China Medical University, Shenyang, Liaoning, People's Republic of China; ${ }^{2}$ Department of Respiratory and Critical Care Medicine, West China Hospital of Sichuan University and Division of Pulmonary Disease, State Key Laboratory of Biotherapy of China, Chengdu, Sichuan, People's Republic of China; ${ }^{3}$ Department of Respiratory and Critical Care Medicine, Peking University, Third Hospital, Beijing, People's Republic of China; ${ }^{4}$ Department of Pulmonary Medicine, Zhongshan Hospital, Fudan University, Shanghai, People's Republic of China; ${ }^{5}$ Department of Pulmonary Medicine, Qilu Hospital, Shandong University, Jinan, Shandong, People's Republic of China; ${ }^{6}$ Department of Pulmonary and Critical Care Medicine, The First Affiliated Hospital of Dalian Medical University, Dalian, Liaonign, People's Republic of China; ${ }^{7}$ Department of Pulmonary and Critical Care Medicine, The First Affiliated Hospital of Xi'an Jiaotong University, Xi'an, Shanxi, People's Republic of China; ${ }^{8}$ Department of Respiratory, First Affiliated Hospital of Harbin Medical University, Harbin, Heilongiiang, People's Republic of China; ${ }^{9}$ Respiratory Department, Tianjin Medical University General Hospital, Tianjin, People's Republic of China; ${ }^{10}$ Department of Pulmonary and Critical Care Medicine, Institute of Respiratory Diseases, Shengjing Hospital of China Medical University, Shenyang, Liaoning, People's Republic of China; "Department of Pulmonary Medicine, Central Hospital Affiliated with Shenyang Medical College, Shenyang, People's Republic of China

Correspondence: Jian Kang

Department of Pulmonary and Critical Care Medicine, Institute of Respiratory Diseases, First Affiliated Hospital of China Medical University, Shenyang, Liaoning, People's

Republic of China

Tel +86-024-83282530

Fax +86-024-83282002

Email kangiian58@I63.com
Purpose: The proportion of atypical pathogens in patient with AECOPD within mainland China is unknown. The objectives of this study were to determine the distribution of atypical pathogens among Chinese patients with AECOPD, to evaluate the clinical characteristics of different atypical pathogen infections, and to compare different detection methods for atypical pathogens.

Patients and Methods: Specimens were collected from patients with AECOPD from March 2016 to November 2018 at eleven medical institutions in eight cities in China. Double serum, sputum, and urine samples were obtained from 145 patients. Serological and nucleic acid tests were used to assess for Mycoplasma pneumonia and Chlamydia pneumoniae; serological, urinary antigen, and nucleic acid tests were applied to detect Legionella pneumophila. The clinical characteristics of atypical pathogen-positive and negative groups were also compared.

Results: The overall positivity rate for Mycoplasma pneumoniae was 20.69\% (30/145), with the highest rate being $20.00 \%$ (29/145) when determined by passive agglutination.The overall positive rates for Chlamydia pneumoniae and Legionella pneumophila were $29.66 \%$ (43/145) and 10.34\% (15/145), respectively. The most common serotype of Legionella pneumophila was type 6 . The maximum hospitalized body temperature, ratio of eosinophils, C-reactive protein (CRP) level, and procalcitonin (PCT) level of the Mycoplasma pneumoniae-positive group were significantly higher than those of the Mycoplasma pneumoniae-negative group. Patients in the Chlamydia pneumoniae-positive group smoked more, had higher proportions of comorbidities and frequent aggravations in the previous two years than those in the Chlamydia pneumoniae-negative group. Furthermore, the forced expiratory volume in one second to forced vital capacity $\left(\mathrm{FEV}_{1} /\right.$ FVC) ratio assessment of lung function was higher, and the concentration of arterial blood bicarbonate $\left(\mathrm{HCO}_{3}{ }^{-}\right)$was lower in the Legionella pneumophila-positive group than in the Legionella pneumophila-negative group.

Conclusion: Overall, atypical pathogens play an important role in AECOPD. Regarding the testing method, serological testing is a superior method to nucleic acid testing.

Keywords: COPD, exacerbations, Mycoplasma pneumoniae, Chlamydia pneumoniae, Legionella pneumophila

\section{Introduction}

Chronic obstructive pulmonary disease (COPD) is a common chronic airway disease that poses a serious health risk to humans. ${ }^{1}$ Acute exacerbations of COPD (AECOPD) result in dramatic deterioration of lung function and significantly 
decreased life quality and are clearly associated with a high patient mortality rate. ${ }^{2,3}$ Respiratory tract infections are the most common cause of AECOPD. ${ }^{4}$ Common atypical pathogens associated with respiratory infections include Mycoplasma pneumoniae, Chlamydia pneumoniae, and Legionella pneumophila. In clinical practice, atypical pathogen infections are usually diagnosed indirectly by serological antibody testing and nucleic acid testing of secretions (sputum) without culturing these pathogens. Thus, although the etiological factors of AECOPD have been discussed in many studies, the prevalence of atypical pathogens in patients with AECOPD varies considerably among studies. ${ }^{5-7}$ Furthermore, few studies have evaluated the prevalence of atypical pathogens among patients with AECOPD in mainland China, which poses a challenge for selecting empirical treatment for these pathogens. In this study, specimens (serum and sputum) were prospectively collected from patients AECOPD from multiple centers, and serological and nucleic acid tests were performed. The distribution of atypical pathogens in patients with AECOPD in mainland China was determined, and the detection methods for these pathogens were compared.

\section{Patients and Methods}

Data from patients with AECOPD were collected from eleven medical institutions in eight cities in China during the period from March 2016 to November 2018. The inclusion and exclusion criteria are as follows:

\section{Inclusion Criteria}

1. Patients meeting the diagnostic criteria for COPD;

2. Patients in the acute exacerbation stage of COPD requiring hospitalization; and

3. Complete collection of eligible sputum specimens and two serum specimens ( $14 \pm 4$ days interval).

\section{Exclusion Criteria}

1. Women who were pregnant or breastfeeding;

2. Patients with bronchiectasis;

3. Patients with active tuberculosis;

4. Patients with aspiration pneumonia or obstructive pneumonia;

5. Patients with a history of hospitalization 2 weeks before the onset of the illness (as the infection at the time of admission may be a hospital-acquired infection);
6. Human immunodeficiency virus (HIV)-positive patients (not required to be tested for HIV)

7. Patients who could not and/or did not understand and/or implement the investigation protocol; and

8. Patients with pneumonia.

This study was conducted in accordance with the Declaration of Helsinki. The protocol was approved by the Ethics Committee of the First Affiliated Hospital of China Medical University.All study participants signed informed consent prior to commencement of the study and gave consent to have their data published.

\section{Demographic and Clinical Data}

The following patient information was collected: 1) basic information: sex, age, body mass index, primary vital signs (including temperature, heart rate, and respiration) on admission, and care unit admission status; 2) incident information: time (days) from the incident to hospital admission, history of suspicious environmental exposures (eg, air conditioning, bathing, rain, tree watering, or oral treatment), travel history 2 weeks before the incident, and details on the prevalence of influenza in the community 2 weeks before the incident; 3) past history: smoking history, drinking history, history of concomitant diseases, usage of long-term inhaled or oral hormone therapy, number of acute exacerbations in the previous two years, lung function (prior six months), COPD assessment test findings, and results of the British modified Medical Research Council (mMRC) scale; 4) laboratory tests: blood gas analysis after hospitalization, routine blood tests, C-reactive protein (CRP), procalcitonin (PCT) and related biochemical tests [eg, alanine aminotransferase (ALT), aspartate aminotransferase (AST), serum albumin (ALB), blood urea nitrogen, serum electrolytes, lactate dehydrogenase (LDH), and creatine kinase (CK)]; and 5) clinical data: mechanical ventilation (including noninvasive ventilation and invasive mechanical ventilation), days of hospitalization, and transfer on the third day of hospitalization.

\section{Microbiology Research}

Sputum Specimens

After admission, spontaneous sputum was collected in a routine manner with or without the use of expectorant. Sputum specimens were collected before antibiotics were administered in the hospital. The collected sputum specimens were included in the study only if they met the 
standards of Gram staining ( $<10$ epithelial cells and $>25$ polymorphonuclear leukocytes). A polymerase chain reaction (PCR) method was applied to detect DNA fragments of Mycoplasma pneumoniae, Chlamydia pneumoniae, and Legionella pneumophila in these specimens.

\section{Paired Serological Specimens}

Serum was collected on admission and 2 weeks $(14 \pm 4$ days) after the initial serum collection for two paired serological examinations.

\section{Urine Specimens}

Morning urine specimens were collected from patients at the time of admission to test for urine antigens of Legionella pneumophila.

\section{Detection of Atypical Pathogens}

QIAamp@DNAmini kit (Qiagen, Germany) was used to extract genomic DNA from the sputum specimens included in the study. DNA fragments of Mycoplasma pneumoniae, Chlamydia pneumoniae, and Legionella pneumophila were detected by PCR using Roche's Mycoplasma pneumoniae, Chlamydia pneumoniae, and Legionella pneumophila (both Legionella pneumophila and non-Legionella pneumophila) kits. Specifically, the 89-bp fragment of the repMp1 gene was detected for Mycoplasma pneumoniae, the 85-bp fragment of the major outer membrane protein gene was detected for Chlamydia pneumoniae, and the 162-bp fragment of the 16S RNA gene was detected for Legionella pneumophila. The result determination criteria are shown in Table 1.

Paired serological specimens included in the study were tested to detect serological antibodies for atypical pathogens.

Serum Mycoplasma pneumoniae antibodies were detected using a Serodia ${ }^{\circledR}$-Myco II Mycoplasma pneumoniae antibody test kit (Fujirebio, Japan) (passive agglutination method). The RIDASCREEN ${ }^{\circledR} \quad$ Mycoplasma pneumoniae IgM kit (R-Biopharm AG, Germany) (enzyme

Table I The Result Determination Criteria of PCR

\begin{tabular}{|l|l|l|l|}
\hline Result & Sample & $\begin{array}{l}\text { Internal } \\
\text { Reference }\end{array}$ & $\begin{array}{l}\text { Negative } \\
\text { Control }\end{array}$ \\
\hline Negative & No amplification & Detectable & Negative \\
\hline Positive & $\begin{array}{l}\text { Amplification CP } \\
<37\end{array}$ & & Negative \\
\hline
\end{tabular}

Notes: If the internal reference is not detected, it indicates PCR failure; If the negative control is positive, it indicates PCR contamination. immunoassay) was used for the detection of Mycoplasma IgM antibodies. ${ }^{8}$

Serum Chlamydia pneumoniae IgG antibodies were detected using a Chlamydia pneumoniae microimmunofluorescence kit (FOCUS, USA) (microimmunofluorescence (MIF) assay).

Serum Legionella pneumophila IgA, IgM, and IgG antibodies (indirect fluorescent antibody types 1-14) were detected using a Legionella pneumophila antibody IgA/IgG/ IgM test kit (EUROIMMUN MedizinischeLabordiagnostika AG, Germany). Serum Legionella pneumophila IgM antibodies were detected using a Legionella pneumophila antibody IgM ELISA test kit (EUROIMMUN MedizinischeLabordiagnostika AG, Germany). ${ }^{9}$ The BINAX NOW ${ }^{\circledR}$ Legionella Urinary Antigen Card kit was used to detect Legionella pneumophila urinary antigens.

\section{Positive Result Determination Criteria}

Mycoplasma pneumoniae: The result is considered to be positive when 1) the antibody titer in the second serum sample is four times higher or lower than that in the first serum sample, 2) IgM is positive, or 3) the nucleic acid test is positive. ${ }^{10-12}$

Chlamydia pneumoniae: The result is considered to be positive when 1) the IgG antibody titer in the second serum sample is four times higher or lower than that in the first serum sample or 2) the nucleic acid test is positive. ${ }^{13-16}$

Legionella pneumophila: The result is considered to be positive when 1) the antibody titer in the second serum sample is four times higher or lower than that in the first serum sample, 2) IgM is positive, 3) the nucleic acid test is positive, or 4) Legionella pneumophila urinary antigen is positive. ${ }^{17,18}$

\section{Statistical Methods}

Statistical analysis was performed using the statistical software SPSS 17.0. Categorical variables are expressed as percentages, and numerical variables are expressed as the mean \pm standard deviation. Continuous variables and categorical variables were evaluated by an independent samples $t$-test and the Chi-square test, respectively, to identify differences among groups. A p-value $<0.05$ was considered statistically significant.

\section{Results}

\section{Basic Information of Patients with AECOPD}

During the study, a total of 366 patients with AECOPD were admitted to the eleven centers, and 145 patients with 
AECOPD were included in the study according to the inclusion and exclusion criteria. The general demographic data are shown in Table 2.

\section{Overall Positive Rate for Atypical Pathogens in Patients with AECOPD}

The overall positive rate for Mycoplasma pneumoniae was $20.69 \%(30 / 145)$, with the highest positive rate being $20.00 \%(29 / 145)$ when determined by passive agglutination. The overall positive rate for Chlamydia pneumoniae was $29.66 \%$ (43/145). The overall positive rate for Legionella pneumophila was $10.34 \%(15 / 145)$, and the most common serotype was type 6 . The specific results for atypical pathogens detected by various methods are shown in Table 3. The serotype results for Legionella pneumophila are shown in Table 4.

\section{Clinical Characteristics of Patients Who Tested Positive for Atypical Pathogens}

The clinical characteristics of patients who tested positive for Mycoplasma pneumoniae, Chlamydia pneumoniae, and Legionella pneumophila are shown in Table 5.

\section{Discussion}

A total of 366 patients were initially included in this study. To improve the reliability of the results of atypical pathogens, only patients with paired serum samples (one obtained on admission and one obtained 2 weeks $(14 \pm 4$ days) later) were included. However, more than half of this initial patient group (221 patients) did not have a second serum sample (14 \pm 4 days) and were thus excluded. There were three main reasons for this: 1) Many patients with mild disease did not stay in hospital for 10 days. 2) Chinese medical insurance policies require that the length

Table 2 General Demographic Data

\begin{tabular}{|l|l|}
\hline Clinical Characteristics & \\
\hline Number of patients & 145 \\
Age in years(Mean \pm SD) & $74.35 \pm 10.07$ \\
Gender (male) & $70.34 \%$ \\
BMI $\left(\mathrm{kg} / \mathrm{m}^{2)}(\right.$ Mean $\pm \mathrm{SD})$ & $22.58 \pm 4.12$ \\
Smoker & $66.21 \%$ \\
\hline Spirometry(post) & \\
FEV $\%$ pred(Mean \pm SD) & $41.81 \pm 19.31$ \\
FVC $\%$ pred(Mean $\pm S D)$ & $59.57 \pm 20.21$ \\
FEV $/$ FVC(Mean $\pm S D)$ & $51.75 \pm 14.35$ \\
Comorbidities & $63.45 \%$ \\
\hline
\end{tabular}

Table 3 The Specific Results of Atypical Pathogens Detected by Various Methods

\begin{tabular}{|c|c|}
\hline \multicolumn{2}{|l|}{ Mycoplasma pneumoniae } \\
\hline Detection method & $\begin{array}{l}\text { Positive rate (positivel } \\
\text { total) }\end{array}$ \\
\hline Passive agglutination & $20.00 \%(29 / 145)$ \\
\hline IgM(enzyme immunoassay) & $2.75 \%(4 / 145)$ \\
\hline PCR(sputum) & $1.75 \%(2 / 1 \mid 4)$ \\
\hline Total & $20.69 \%(30 / 145)$ \\
\hline \multicolumn{2}{|l|}{ Chlamydia pneumoniae } \\
\hline Detection method & $\begin{array}{l}\text { Positive rate (positivel } \\
\text { total) }\end{array}$ \\
\hline $\begin{array}{l}\text { Microimmunofluorescence } \\
\text { assay(MIF) }\end{array}$ & $29.66 \%(43 / 145)$ \\
\hline PCR(sputum) & $0 \%(0 / I \mid 4)$ \\
\hline Total & $29.66 \%(43 / 145)$ \\
\hline \multicolumn{2}{|l|}{ Legionella pneumophila } \\
\hline Detection method & $\begin{array}{l}\text { Positive rate (positivel } \\
\text { total) }\end{array}$ \\
\hline Indirect fluorescent & $10.34 \%(15 / 145)$ \\
\hline $\operatorname{lgM(ELISA)}$ & $0.69 \%(1 / 145)$ \\
\hline PCR(sputum) & $0 \%(0 / I I 5)$ \\
\hline Urinary Antigen & $0 \%(0 / 145)$ \\
\hline Total & $10.34 \%(15 / 145)$ \\
\hline
\end{tabular}

of stay cannot be too long (once patients have improved, they may return to local hospitals for further treatment). 3) Some patients declined to have blood collected again after they improved. Thus, the selected patients may have had worse lung function (mean forced expiratory volume in one second (FEV1), 41.81\%) and longer hospitalization

Table 4 Frequency of the Various Legionella pneumophila Serotype Identified in the II Hospital Admissions

\begin{tabular}{|l|l|}
\hline Legionella pneumophila & $\mathbf{N}(\%)$ \\
\hline Legionella pneumophila-6 & $9(60.00 \%)$ \\
Legionella pneumophila-I4 & $5(33.33 \%)$ \\
Legionella pneumophila-I & $4(26.67 \%)$ \\
Legionella pneumophila-7 & $3(20.00 \%)$ \\
Legionella pneumophila-8 & $3(20.00 \%)$ \\
Legionella pneumophila-I0 & $3(20.00 \%)$ \\
Legionella pneumophila-I2 & $3(20.00 \%)$ \\
Legionella pneumophila-4 & $2(13.33 \%)$ \\
Legionella pneumophila-II & $2(13.33 \%)$ \\
Legionella pneumophila-2 & $1(6.67 \%)$ \\
Legionella pneumophila-5 & $1(6.67 \%)$ \\
Two serotypes positive & $3(20.00 \%)$ \\
@three serotypes positive & $6(40.00 \%)$ \\
\hline
\end{tabular}




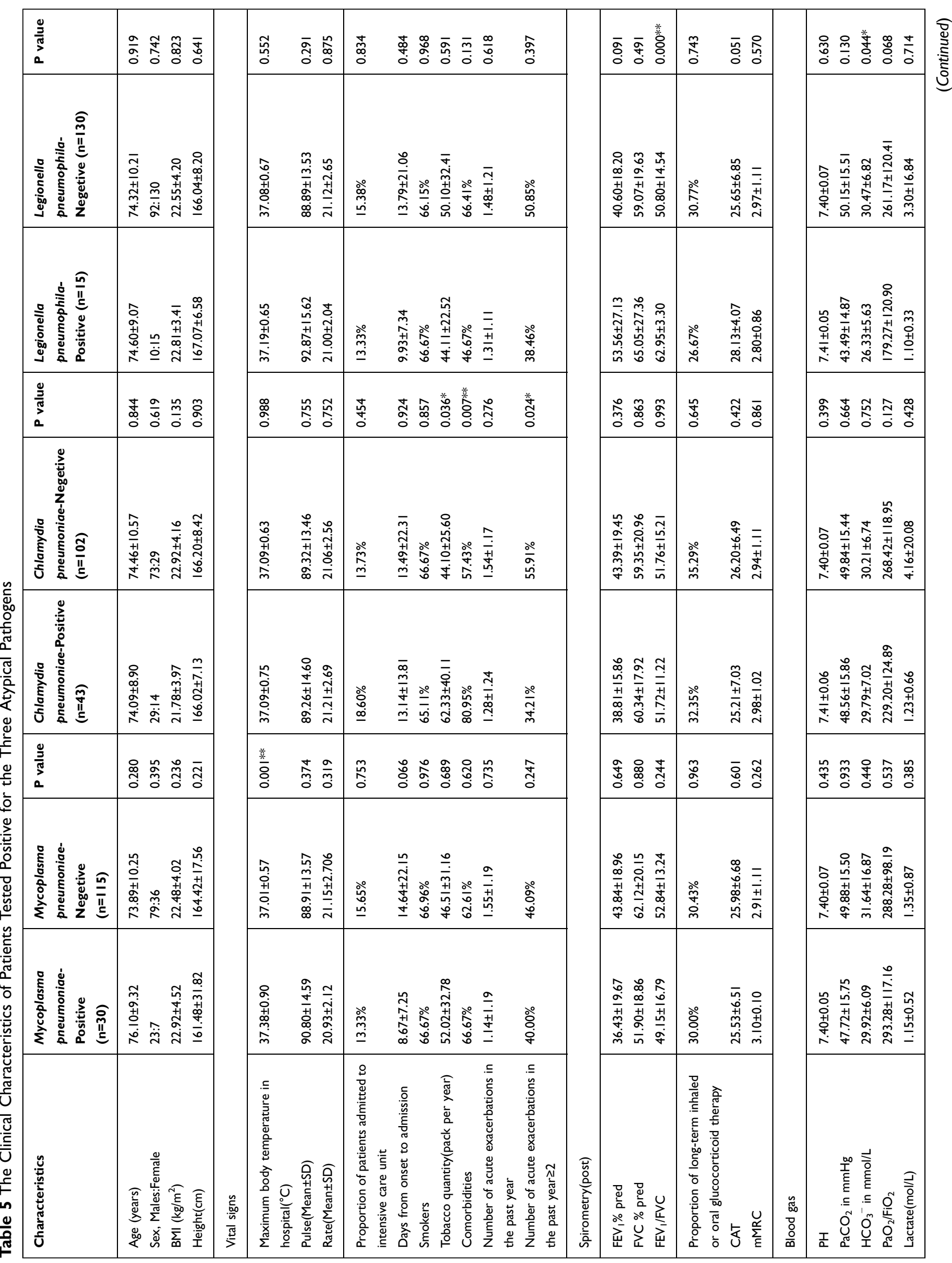




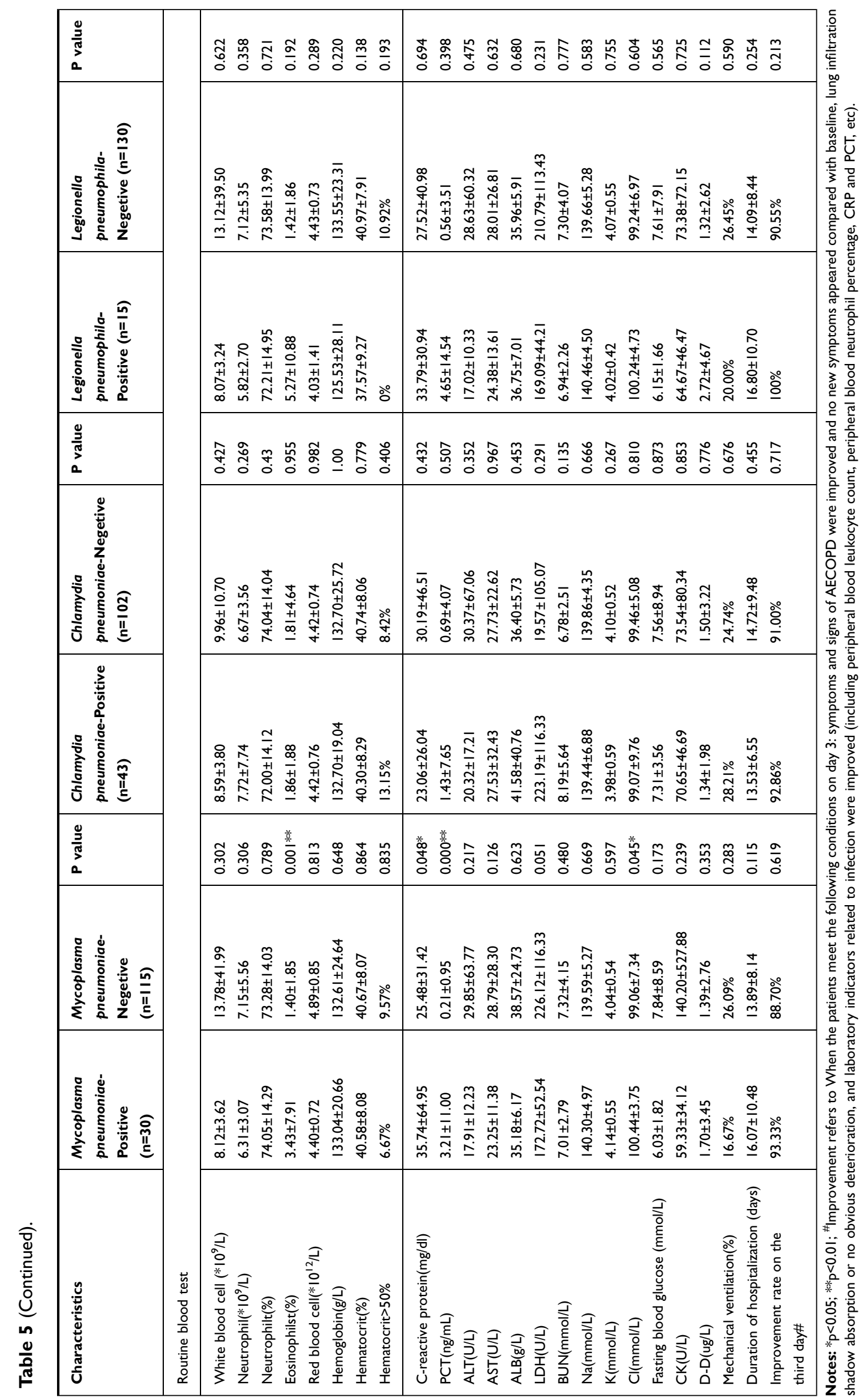


times (mean hospitalization length, $\sim 14$ days). However, this was determined by the design of this study.

In this study, all patients had chest radiographs or lung CT scans performed. If the patient's chest radiographs or lung CT scan showed new patches, patchy infiltrates, or interstitial changes in the lungs, the patient was excluded. Thus, some patients with COPD combined with pneumonia were excluded, which ensured that all patients in the group had AECODP. This is also one reason why few patients were selected.

Laboratory diagnostic methods for atypical pathogens include culture, serum antibody detection, and nucleic acid detection. Etiological identification of conventional bacterial pathogens causing AECOPD relies on sputum culture. However, for atypical pathogens, due to difficulty in isolation and their slow growth, which make it difficult to analyze the results in a short period of time, sputum cultures are rarely used in clinical practice. ${ }^{19,20}$ In this study, we used a variety of detection methods such as serology, PCR, and urine antigen testing for three atypical pathogens. We listed the sensitivity and specificity of the detection methods in Table 6 after consulting many studies. $^{8-10,15,16,18,20}$ Serology-based specific antibody testing is the traditional approach for identifying atypical pathogen infections. In order to make the serological antibody results better and more accurately reflect the infection situation of the patients, the patients we collected all had double sera in this study. When there was a 4-fold change in the antibody of double sera, the test result of atypical pathogens was considered positive. The change of this antibody could better reflect the patient's recent infection of atypical pathogens. ${ }^{8,14,18}$ Another the positive patients were IgM positive, and IgM antibodies are recognized as early antibodies when the patient were infected by atypical pathogens, so it can also reflect the recent infection of the patients. ${ }^{8,19-21}$ We listed the sensitivity and specificity of the detection methods in Table 6 by consulting many literatures.

The specificity of nucleic acid tests of secretions (PCR method) is high, but its sensitivity varies considerably among studies. ${ }^{10,20,22}$ We believe that this variation is related to the collection method and site of the specimens subjected to PCR testing. The diagnostic performance of Roche Mycoplasma pneumoniae, Chlamydia pneumoniae, and Legionella pneumophila multiplex Lightmix RT-PCR kit has been evaluated by Wagner et $\mathrm{al}^{23}$ and showed identical performance characteristics (specificity and sensitivity) to in-house singleplex RT-PCRs for pathogen

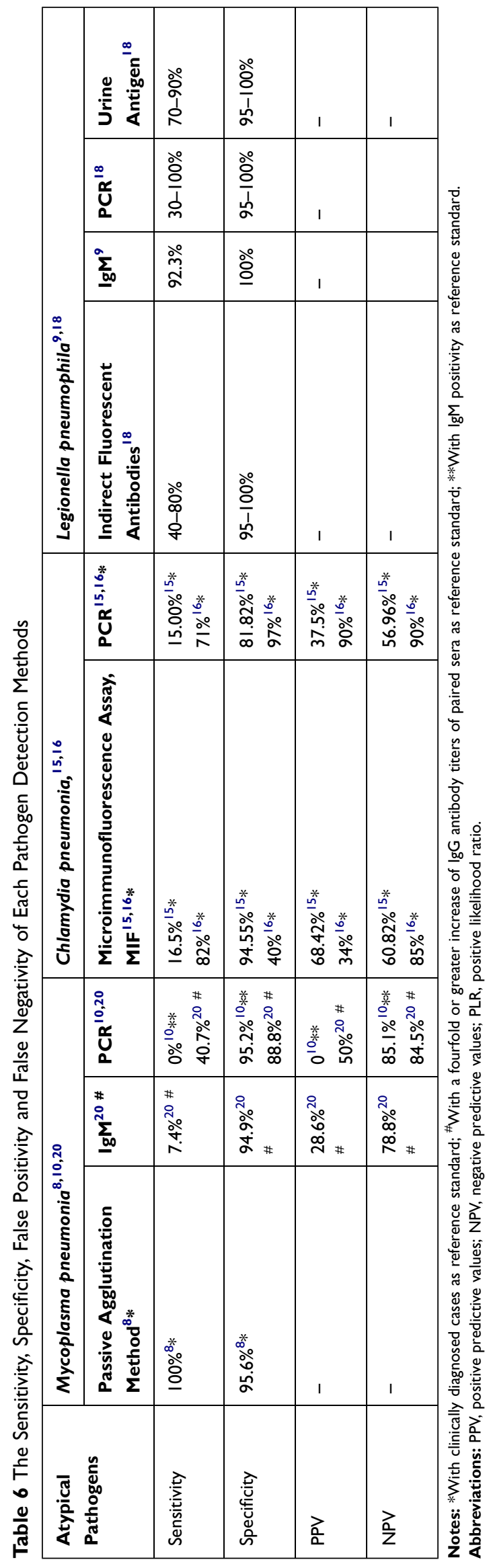


detection. Wagner ${ }^{24}$ and Orozco-Hoyos ${ }^{25}$ used the kit to detect Mycoplasma pneumoniae, Chlamydia pneumoniae. Relevant studies have discussed the sensitivity of PCR for detecting atypical sputum pathogens in patients with AECOPD and obtained a very low positive rate, ${ }^{20-22,26}$ which is consistent with the results of the our study. A study by Diederen et $\mathrm{al}^{27}$ showed that all 126 sputum samples of patients with AECOPD were negative for Mycoplasma pneumonia and Chlamydia pneumonia DNA, while one sample was positive for Legionella pneumophila and non-pneumophila DNA. The sensitivity of PCR was lower than that of serology, as shown in Table 6.

Overall, based on the results of this study, the sensitivity of serological testing is superior to that of sputum nucleic acid testing for atypical pathogens.Diederen's findings are consistent with our research.

Previous studies have indicated that AECOPD induced by infectious causes account for approximately $40 \%$ of the overall number of AECOPD cases. ${ }^{28}$ In this study, we observed an overall positivity rate of $20.69 \%$ (30/145), 29.66\% (43/145), and 10.34\% (15/145) for Mycoplasma pneumoniae, Chlamydia pneumoniae, and Legionella pneumophila, respectively. However, the proportions of atypical pathogens identified in patients with AECOPD are different in different studies due to the use of varied detection methods in different countries and regions.

The detection rate of Mycoplasma pneumoniae was $0.2-6.0 \% \%^{4,29-35}$ in a previous study. Varma-BasilM ${ }^{35}$ conducted a study involving outpatients with AECOPD. The serological test results showed that the positive rate for Mycoplasma pneumoniae was $16 \%$ (compared with $18.62 \%$ by serum testing in this study). The detection rate for Chlamydia pneumoniae was $0.3-44.7 \% .^{5,6,31,32,34,36-39}$ A study by Karnak et al ${ }^{37}$ identified Chlamydia pneumoniae in $34 \%$ of patients with AECOPD. There are few studies onLegionella pneumophila. A study by Lieberman et $\mathrm{al}^{40}$ detected Legionella in $16.7 \%$ of patients. The findings of the abovementioned studies are similar to the results of this study.

Due to the chronic bacterial colonization in the lower respiratory tract in patients with COPD patients, ${ }^{41}$ the proportions of concomitant routine infections and atypical pathogens may be higher than expected.

Notably, in previous epidemiological studies, type 1 Legionella pneumophila infection was the most common among patients with symptomatic Legionella pneumophila pneumonia. ${ }^{18,40}$ Among the 15 cases of Legionella infection in this study, only three cases were identified as
Legionella type 1, whereas nine were Legionella type 6. Legionella type 1 is generally considered to be more pathogenic than other serotypes of Legionella, but none of the 15 patients showed typical symptoms of Legionella infection, such as high fever, cough with orange sputum, muscle aches, abdominal pain, or diarrhea. This finding suggests that for patients with AECOPD, the use of a urinary antigen kit that detects Legionella type 1 alone may not be sufficient to clarify whether a concomitant pulmonary infection caused by Legionella pneumophila is present.

Due to their sensitivity and specificity limitations, assays that do not rely on pathogen culture pose a clinical challenge for determining treatment strategies for atypical pathogens. We believe that empirical treatment of atypical pathogens may be beneficial if certain clinical characteristics are suggestive of infection. In the present study, the maximum body temperature, eosinophil percentage, CRP level, and PCT level were significantly higher in patients with AECOPD who tested positive for Mycoplasma pneumoniae than in those who tested negative. This suggests that patients with AECOPD concomitantly infected with Mycoplasma pneumoniae have more severe airway hyperresponsiveness and systemic inflammation; the specific mechanisms underlying this phenomenon need to be clarified in further studies. Although it is generally accepted that among atypical pathogens, Legionella pneumophila is more likely to cause severe sepsis, surprisingly, this phenomenon was not observed in patients with AECOPD who tested positive for Legionella pneumophila. Patients with AEOCPD who tested positive for Legionella pneumophila infection had a higher forced expiratory volume in one second to forced vital capacity (FEV1/FVC) ratio assessment of lung function and a lower arterial blood bicarbonate $\left(\mathrm{HCO}_{3}{ }^{-}\right)$concentration, suggesting that patients with COPD with mild pulmonary obstruction who do not need to be homebound and therefore have better mobility may be more susceptible to exposure to Legionella pneumophila. There were no statistically significant clinical characteristics observed in patients with AECOPD with Chlamydia pneumoniae infection.

\section{Conclusion}

In summary, we believe that the proportion of concomitant infection by atypical pathogens may be very high in patients with infection-induced AECOPD. Serological testing remains the most reliable test for atypical pathogens. 


\section{Acknowledgments}

This work is supported by the National Key Research and Development Program of China (2016YFC1304500) andLiaoning Provincial Health Commission Provincial Hospital Clinical Diagnosis and Treatment Capacity Construction Project (LNCC-B01-2015).

\section{Disclosure}

The authors report no conflicts of interest in this work.

\section{References}

1. Lõpez-Campos JL, Tan W, Soriano JB. Global burden of COPD Respirology. 2016;21(1):14-23. doi:10.1111/resp.12660

2. Aaron SD, Vandemheen KL, Clinch JJ, et al. Measurement of short-term changes in dyspnea and disease-specific quality of life following an acute COPD exacerbation. Chest. 2002;121(3):688-696. doi:10.1378/ chest.121.3.688

3. Soler-Cataluña JJ, Má MG, Román Sánchez P, Salcedo E, Navarro M, Ochando R. Severe acute exacerbations and mortality in patients with chronic obstructive pulmonary disease. Thorax. 2005;60(11):925-931. doi:10.1136/thx.2005.040527

4. Mackay AJ, Hurst JR. COPD exacerbations. causes, prevention, and treatment. Immunol Allergy Clin North Am. 2013;33(1):95-115. doi:10.1016/j.iac.2012.10.006

5. Domenech A, Puig C, Martí S, et al. Infectious etiology of acute exacerbations insevere COPD patients. $J$ Infect. 2013;67(6):516-523. doi:10.1016/j.jinf.2013.09.003

6. Nakou A, Papaparaskevas J, Diamantea F, Skarmoutsou N, Polychronopoulos V, Tsakris A. A prospective study on bacterial and atypical etiology of acute exacerbation in chronic obstructive pulmonary disease. Future Microbiol. 2014;9(11):1251-1260. doi:10.2217/ fmb. 14.90

7. Jung CY, Choe YH, Lee SY, et al. Use of serology and polymerase chain reaction to detect atypical respiratory pathogens during acute exacerbation of chronic obstructive pulmonary disease. Korean J Intern Med. 2018;33(5):941-951. doi:10.3904/kjim.2017.279

8. Aubert G, Pozzetto B, Gaudin OG, Hafid J, Mbida AD, Ros A. Evaluation of five commercial tests: complement fixation, microparticle agglutination, indirect immunofluorescence, enzyme-linked immunosorbent assay and latex agglutination, in comparison to immunoblotting for Mycoplasma pneumoniae serology. Ann Biol Clin. 1992;50(8):593-597. doi:10.1007/s00429-002-0246-9

9. Diederen BMW, Kluytmans JAJW, Peeters MF. Evaluation of Vircell enzyme-linked immunosorbent assay and indirect immunofluorescence assay for detection of antibodies against Legionella pneumophila. Clin Vaccine Immunol. 2006;13(3):361-364. doi:10.1128/CVI.13.3.361364.2006

10. Montagnani F, Rossetti B, Vannoni A, Cusi MG, De Luca A. Laboratory diagnosis of Mycoplasma pneumoniae infections: data analysis from clinical practice. New Microbiol. 2018;41(3):203-207.

11. Waites KB, Xiao L, Liu Y, Balish MF, Atkinson TP. Mycoplasma pneumoniae from the respiratory tract and beyond. Clin Microbiol Rev. 2017;30(3):747-809. doi:10.1128/CMR.00114-16

12. Atkinson TP, Balish MF, Waites KB. Epidemiology, clinical manifestations, pathogenesis and laboratory detection of Mycoplasma pneumoniae infections. FEMS Microbiol Rev. 2008;32(6):956-973. doi:10.1111/j.1574-6976.2008.00129.x

13. File T, Bartlett J, Cassell G, et al. The importance of Chlamydia pneumoniae as a pathogen: the 1996 consensus conference on Chlamydia pneumoniae infections. Infect Dis Clin Pract. 1997;6(2): S28-S31. doi:10.3109/15412555.2011.636407
14. Grayston JT, Campbell LA, Kuo CC, et al. A new respiratory tract pathogen: Chlamydia pneumoniae strain TWAR. J Infect Dis. 1990;161(4):618-625. doi:10.1093/infdis/161.4.618

15. Al-Aydie SN, Obeidat NM, Al-Younes HM. Role of chlamydia pneumoniae in community-acquired pneumonia in hospitalized Jordanian adults. $J$ Infect Dev Ctries. 2016;10(3):227-236. doi: $10.3855 /$ jidc. 6590

16. Benitez AJ, Thurman KA, Diaz MH, Conklin L, Kendig NE, Winchell JM. Comparison of real-time PCR and a microimmunofluorescence serological assay for detection of Chlamydophila pneumoniae infection in an outbreak investigation. J Clin Microbiol. 2012;50(1):151-153. doi:10.1128/JCM.05357-11

17. Gunasekaran K, Ahmad M, Rehman S, Thilagar B. Impact of a positive viral polymerase chain reaction on outcomes of chronic obstructive pulmonary disease (COPD) exacerbations. Int J Environ Res Public Health. 2020;17:8072. doi:10.3390/ijerph17218072

18. Mercante JW, Winchell JM. Current and emerging Legionella diagnostics for laboratory and outbreak investigations. Clin Microbiol Rev. 2015;28(1):95-133. doi:10.1128/CMR.00029-14

19. Gao CH, Ji BJ, Han C, Wang MS. Comparison of enzyme-linked immunosorbent assay with indirect immunofluorescence assay for the diagnosis of Mycoplasma pneumoniae infection. J Clin Lab Anal. 2019;33(2):e22677. doi:10.1002/jcla.22677

20. Qu J, Gu L, Wu J, et al. Accuracy of IgM antibody testing, FQ-PCR and culture in laboratory diagnosis of acute infection by Mycoplasma pneumoniae in adults and adolescents with community-acquired pneumonia. BMC Infect Dis. 2013;13:172. doi:10.1186/1471-2334$13-172$

21. Kashyap B, Kumar S, Sethi GR, Das BC, Saigal SR. Comparison of PCR, culture \& serological tests for the diagnosis of Mycoplasma pneumoniae in community-acquired lower respiratory tract infections in children. Indian J Med Res. 2008;128(2):134-139. doi:10.1128/ JCM.37.1.14-17.1999

22. Shimizu K, Yoshii Y, Morozumi M, et al. Pathogens in COPD exacerbations identified by comprehensive real-time PCR plus older methods. Int J COPD. 2015;10(1):2009-2016. doi:10.2147/COPD.S82752

23. Wagner K, Springer B, Imkamp F, Opota O, Greub G, Keller PM. Detection of respiratory bacterial pathogens causing atypical pneumonia by multiplex Lightmix ${ }^{\circledR}$ RT-PCR. Int $J$ Med Microbiol. 2018;308(3):317-323. doi:10.1016/j.ijmm.2018.01.010

24. Wagner K, Imkamp F, Pires VP, Keller PM. Evaluation of Lightmix Mycoplasma macrolide assay for detection of macrolide-resistant Mycoplasma pneumoniae in pneumonia patients. Clin Microbiol Infect. 2019;25(3):383.e5-383.e7. doi:10.1016/j.cmi.2018.10.006

25. Orozco-Hoyos N, Baena A, Montoya-Ruiz C, Sánchez GI, Restrepo E. Prevalencia de Chlamydia trachomatis en la población femeninaasintomáticaatendidaen los servicios de citología cervical de tresinstitucionesprestadoras de servicios de saluden Medellín, Colombia. Biomédica. 2020;40(3):534-545. doi:10.7705/biomedica.5225

26. Nilsson AC, Björkman P, Persson K. Polymerase chain reaction is superior to serology for the diagnosis of acute Mycoplasma pneumoniae infection and reveals a high rate of persistent infection. $B M C$ Microbiol. 2008;8:93. doi:10.1186/1471-2180-8-93

27. Diederen BMW, van der Valk PD, Kluytmans JA, Peeters MF, Hendrix R. The role of atypical respiratory pathogens in exacerbations of chronic obstructive pulmonary disease. Eur Respir J. 2007;30(2):240-244. doi:10.1183/09031936.00012707

28. Boixeda R, Rabella N, Sauca G, et al. Microbiological study of patients hospitalized for acute exacerbation of chronic obstructive pulmonary disease (AE-COPD) and the usefulness of analytical and clinical parameters in its identification (VIRAE study). Int $J$ Chron Obstruct Pulmon Dis. 2012;7:327-335. doi:10.2147/copd.s30568

29. Arnold FW, Summersgill JT, Lajoie AS, et al. A worldwide perspective of atypical pathogens in community-acquired pneumonia. Am J Respir Crit Care Med. 2007;175(10):1086-1093. doi:10.1164/ rccm.200603-350OC 
30. Mandell LA, Wunderink RG, Anzueto A, et al. Infectious diseases society of America/American thoracic society consensus guidelines on the management of community-acquired pneumonia in adults. Clin Infect Dis. 2007;44(Supplement 2):S27-S72. doi:10.1086/ 511159

31. Lieberman D, Ben-Yaakov M, Lazarovich Z, Ohana B, Boldur I. Chlamydia pneumoniae infection in acute exacerbations of chronic obstructive pulmonary disease: analysis of 250 hospitalizations. Eur J Clin Microbiol Infect Dis. 2001;20(10):698-704. doi:10.1007/ s100960100596

32. Seemungal T, Harper-Owen R, Bhowmik A, et al. Respiratory viruses, symptoms, and inflammatory markers in acute exacerbations and stable chronic obstructive pulmonary disease. Am J Respir Crit Care Med. 2001;164(9):1618-1623. doi:10.1164/ ajrccm.164.9.2105011

33. Messous S, Trabelsi I, Grissa MH, Nouira S, Pozzetto B, Mastouri M. Prevalence of Chlamydophila pneumoniae and Mycoplasma pneumoniae IgM and IgG antibodies in Tunisian patients presenting with exacerbation of chronic obstructive pulmonary disease. Médecine Mal Infect. 2017;47(2):158-163. doi:10.1016/ j.medmal.2016.12.002

34. Meloni F, Paschetto E, Mangiarotti P, et al. Acute Chlamydia pneumoniae and Mycoplasma pneumoniae infections in community-acquired pneumonia and exacerbations of COPD or asthma: therapeutic considerations. J Chemother. 2004;16(1):70-76. doi:10.1179/joc.2004.16.1.70
35. Varma-Basil M, Dwivedi SKD, Kumar K, et al. Role of Mycoplasma pneumoniae infection in acute exacerbations of chronic obstructive pulmonary disease. $J$ Med Microbiol. 2009;58(3):322-326. doi:10.1099/jmm.0.003335-0

36. White AJ, Gompertz S, Stockley RA. Chronic obstructive pulmonary disease. 6: the aetiology of exacerbations of chronic obstructive pulmonary disease. Thorax. 2003;58(1):73-80. doi:10.1136/ thorax.58.1.73

37. Karnak D, Bengsun S, Beder S, Kayacan O. Chlamydia pneumoniae infection and acute exacerbation of chronic obstructive pulmonary disease (COPD). Respir Med. 2001;95(10):811-816. doi:10.1053/ rmed.2001.1159

38. Seemungal TAR, Wedzicha JA, MacCallum PK, Johnston SL, Lambert PA. Chlamydia pneumoniae and COPD exacerbation. Thorax. 2002;57(12):1087-1088. doi:10.1136/thorax.57.12.1087-a

39. Hutchinson AF, Ghimire AK, Thompson MA, et al. A community-based, time-matched, case-control study of respiratory viruses and exacerbations of COPD. Respir Med. 2007;101 (12):2472-2481. doi:10.1016/j.rmed.2007.07.015

40. Lieberman D, Lieberman D, Shmarkov O, et al. Serological evidence of Legionella species infection in acute exacerbation of COPD. Eur Respir J. 2002;19(3):392-397. doi:10.1183/09031936.02.02042002

41. Brightling C, Greening N. Airway inflammation in COPD: progress to precision medicine. Eur Respir J. 2019;54(2):1900651. doi:10.1183/13993003.00651-2019

\section{Publish your work in this journal}

The International Journal of COPD is an international, peer-reviewed journal of therapeutics and pharmacology focusing on concise rapid reporting of clinical studies and reviews in COPD. Special focus is given to the pathophysiological processes underlying the disease, intervention programs, patient focused education, and self management protocols. This journal is indexed on PubMed Central, MedLine and CAS. The manuscript management system is completely online and includes a very quick and fair peer-review system, which is all easy to use. Visit http://www.dovepress.com/testimonials.php to read real quotes from published authors. 